\title{
Comprehensive evaluation of combining CFD simulation and entropy weight to predict natural ventilation strategy in a sliding cover solar greenhouse
}

\author{
$\mathrm{He} \mathrm{Li}^{1}$, Dong $\mathrm{Ji}^{2}$, Xi Hu${ }^{2}$, Tian Xie${ }^{2}$, Weitang Song ${ }^{1}$, Subo Tian ${ }^{2,3 *}$ \\ (1. College of Water Resources and Civil Engineering, China Agricultural University, Beijing 100083, China; \\ 2. College of Engineering, Shenyang Agricultural University, Shenyang 110866, China; \\ 3. Key Laboratory of Protected Horticulture, Ministry of Education, Shenyang Agricultural University, Shenyang 110866, China)
}

\begin{abstract}
This study proposed a comprehensive evaluation system to incorporate the contribution of both numerical simulation and statistical decision theory in ventilation performance assessment. A high-resolution model based on the finite volume approach was established to analyze the influence of rotation angles (i.e., side vent flip angle and roof vent flip angle) of the rack-and-pinion ventilated structure on the greenhouse microclimate. The water circulating system and tomato seeding canopies were considered. Heat removal efficiency and mean age of air were employed as quantitative attributes to reflect the internal thermal environment and the airflow organization in the sliding cover solar greenhouse. The simulation model was verified with the temperature profile measured and the average relative error was $1.74 \%$. The results demonstrate that the rotating angles of ventilation schemes have a substantial impact on the microclimate and inhomogeneity of the tomato seeding canopies. The results suggest the average velocity and its inhomogeneity are the crucial predictors, and their entropy weight values are 0.231 and 0.218 , respectively. The relative degree of membership of the side vent flip angle of $45^{\circ}$ is $36 \%$ and $97 \%$ higher than that of the side vent flip angle of $35^{\circ}$ and the side vent flip angle of $25^{\circ}$, respectively. This study can provide a reference to evaluate the ventilated strategies of the sliding cover solar greenhouse for the regional and central government. Keywords: sliding cover solar greenhouse, natural ventilation, CFD simulation, entropy weight, comprehensive evaluation DOI: $10.25165 /$ j.ijabe.20211406.6793
\end{abstract}

Citation: Li H, Ji D, Hu X, Xie T, Song W T, Tian S B. Comprehensive evaluation of combining CFD simulation and entropy weight to predict natural ventilation strategy in a sliding cover solar greenhouse. Int J Agric \& Biol Eng, 2021; 14(6): $213-221$.

\section{Introduction}

Solar greenhouses are innovative horticultural cultivation facilities widely used in the integrated production of diverse vegetables in Northeast China, with the advantages of energy conservation and pest prevention ${ }^{[1,2]}$. It provides an appropriate plant growth environment through the application of systematic management and microclimate control technology ${ }^{[3-5]}$. It is more important to avoid the internal environment limited by external climate change and the scarcity of natural resources compared with field cultivation ${ }^{[6]}$. Greenhouse microclimate regulation has been implemented related to greenhouse geometry ${ }^{[7]}$, wall material and configuration structure $^{[8]}$, ventilation management system ${ }^{[9]}$, energy collection and conversion system ${ }^{[10]}$, crop development model ${ }^{[11]}$, dehumidification design and heat preservation system ${ }^{[12]}$. Therefore, a reliable design decision of greenhouse microclimate combined with airflow distribution and energy conversion is

\section{Received date: 2021-05-25 Accepted date: 2021-10-09}

Biographies: $\mathbf{H e ~ L i}, \mathrm{PhD}$ candidate, research interest: facility horticulture and greenhouse thermal environment, CFD simulation, Email: lihe55@126.com; Dong Ji, PhD candidate, research interest: agriculture intelligent equipment, Email:1056292197@qq.com; Xi Hu, Master, research interest: precision agriculture, Email: 2226815118@qq.com; Tian Xie, Master, research interest: agricultural mechanization engineering, Email: 1486211919@qq.com; Weitang Song, $\mathrm{PhD}$, Professor, research interest: facility horticulture and agriculture intelligent equipment, Email: songchali@cau.edu.cn.

*Corresponding author: Subo Tian, PhD, Professor, research interest: facility horticulture and agriculture intelligent equipment, agricultural engineering. College of Engineering, Shenyang Agricultural University, Shenyang 110866, China. Tel: +86-13940428180, Email: tiansubo@syau.edu.cn. imperative to achieve high yield and quality of crops, and provide a certain guarantee for solving the problem of urgent food shortage.

The primary variables that determine the microclimate regulation are temperature, humidity, radiation intensity, carbon dioxide concentration and air movement ${ }^{[13,14]}$. Especially for tomato seedlings canopies, trying to control the canopy airflow rate between $0.2-1.0 \mathrm{~m} / \mathrm{s}$ can improve the stagnant airflow diffusion of the boundary layer on the leaf surface, and realize the optimization function of the plant photosynthesis and respiration ${ }^{[15]}$. Meanwhile, the temperature beyond the tolerance limits seriously inhibits crop growth, and the existing technology can completely achieve the purpose of cooling, including fan-and-pad cooling system $^{[16]}$, evaporative cooling system ${ }^{[17]}$, water circulation system ${ }^{[18]}$, natural and forced ventilation ${ }^{[19,20]}$. Natural ventilation is mainly driven by external wind and thermal buoyancy forces to enhance economic benefits, which is an energy-efficient cooling strategy for the microclimate control of greenhouses ${ }^{[21]}$. The specific characteristic of conventional natural ventilation in greenhouses is that the internal flow field of air circulation is formed based on the pressure difference between the air introduced on the windward side and the air discharged on the leeward side ${ }^{[22,23]}$. However, researchers mostly consider the response feedback of natural ventilation structure, ventilation opening, location, and lack a comprehensive evaluation decision model to analyze the uniformity of environmental parameters and interactive effects of crop models.

Interactions of environmental parameters are complicated in greenhouse production when associated with different ventilation scenarios and refrigeration systems ${ }^{[24,25]}$. Furthermore, adequate labor consumption and materials are required to obtain specified 
environmental variables in field trials, while some high-cost investment innovation facilities do not have specific references prior to infrastructure construction. Computational fluid dynamics (CFD) can quantitatively control the artificial environmental parameters in the greenhouse, and thoroughly capture the visual representation of simulated microclimate ${ }^{[26,27]}$. The methodology has been verified to be an efficient engineering tool for the parametric investigation of greenhouse thermal and airflow characteristics or complex issues considered ${ }^{[28]}$. An extensive overview of ventilation configuration of greenhouses involving experiments and CFD technology has been approached ${ }^{[29]}$. According to the simplification conditions, grid discretization schemes and physical models, numerical simulation is repeatedly performed by computational programs to analyze energy conversion and reflect the air circulation of ventilation schemes. Based on the analysis, inferred multi-index evaluation criteria are difficult to thoroughly evaluate the fluid dynamics problem. Generally, environmental variables are diverse and have a lot of uncertainty which could be dealt with by applying entropy weight theory ${ }^{[30]}$. In probability theory, entropy weight is a statistical decision-theoretic method to calculate objective weights of criteria, originally developed by Claude Shannon ${ }^{[31]}$. Information entropy employs the average intrinsic information in multiple independent factors to quantify the weight values of variables and has higher practicability and credibility contrasted to subjective assessment. This methodology systematically reflects the resolution of parameters and has been fully endorsed by some research fields, including environmental science, transport system, agriculture engineering ${ }^{[32-34]}$. Zhang et al. ${ }^{[35]}$ suggested approaching both aspects by intensive integration of CFD and weighted entropy analysis in terms of optimizing the wall of Chinese solar greenhouses. Nevertheless, this numerical study ignored the ventilation conditions and the energy exchange of the crop canopy. Moreover, there is a lack of relevant research on ventilation regulation in sliding cover solar greenhouses. In order to realize the exhaust management, traditional microclimate control systems trigger the ventilation machinery to the maximum operating limit but do not accurately reflect the requirements of internal energy conversion and external wind characteristics on the ventilation strategy.

The object of this study was to propose a comprehensive evaluation system to incorporate the contribution of both numerical simulation and statistical decision theory in ventilation performance assessment. Note that this study is an extension of earlier greenhouse microclimate studies on the ventilation scenarios. Early studies have elaborated the influence of ventilation form, external wind speed and wind direction on greenhouse microclimate. ${ }^{[36]}$. The numerical model has been verified by monitoring temperature data under ventilation conditions. The water circulating system and tomato seeding canopies were considered. A parametric evaluation system was constructed that included multiple indicators (i.e., airflow behavior, thermal distribution, the mean age of air and canopy inhomogeneity). Moreover, it is necessary to examine and predict the microclimate distribution of the solar greenhouse during the early design phase.

\section{Methods and model development}

\subsection{Greenhouse description}

The east-west oriented greenhouse is located in the scientific research base of Shenyang Agriculture University (latitude $41.8^{\circ} \mathrm{N}$, longitude $123.4^{\circ} \mathrm{E}$, altitude $42 \mathrm{~m}$ ). The greenhouse is a semicircular galvanized steel structure of $5.2 \mathrm{~m}$, and the roof angle is $45^{\circ}$. A $0.2 \mathrm{~mm}$ thick polyolefin film with a light transmittance of $93 \%$ covered the south roof. In order to address energy capture and balance features, the greenhouse covered with rock wool colored steel plate for thermal insulation has been designed ${ }^{[37]}$. The enclosure structure composed of traditional brick walls is completely replaced by a water circulating system to collect excess solar energy. The accumulated solar energy is released at nighttime through the water circulation system. The circulating groundwater with a temperature of $17^{\circ} \mathrm{C}$ is implemented at noon in summer ${ }^{[36]}$. The rack-and-pinion ventilated structure is adopted for a continuous roof vent and spaced side vents. Tomato seedlings grow in planting troughs and the soil surface inside the greenhouse is covered with black film. The relative humidity of indoor air is low at the early stage of seedling, and the humidity environment is ignored. The profiles of the target greenhouse and principal components are shown in Figure 1.

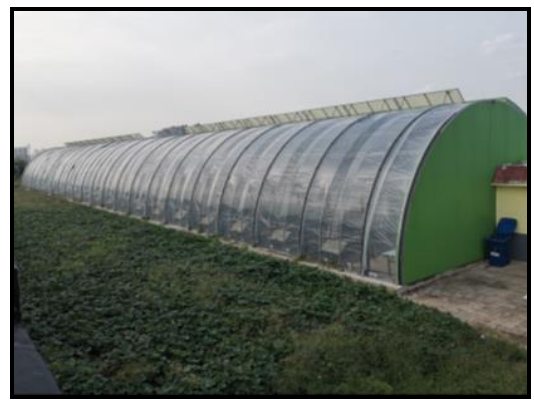

a. General view

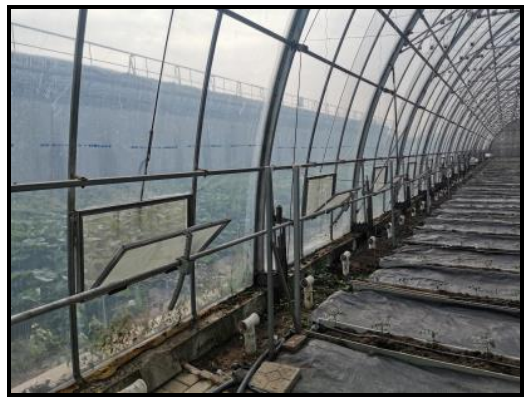

d. Side vent

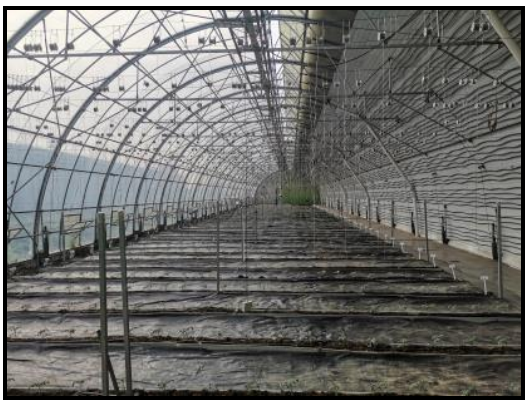

b. Internal layout

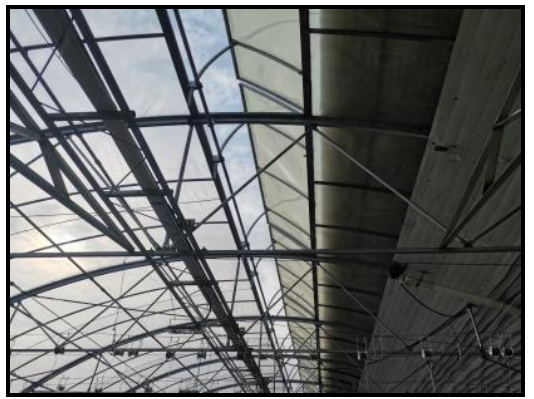

e. Roof vent

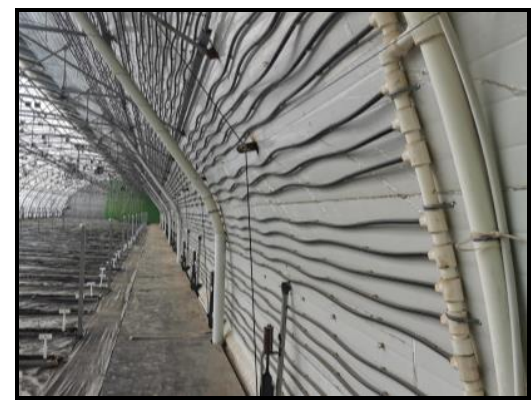

c. Water circulating system

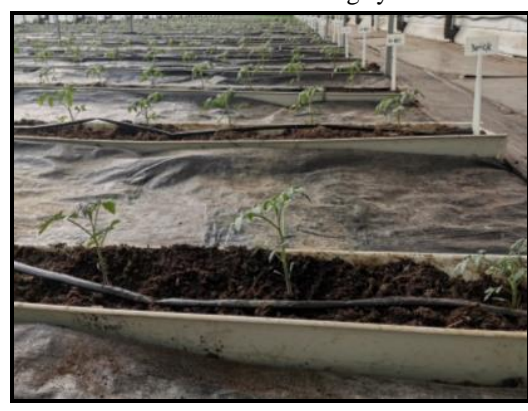

f. Tomato seedlings

Figure 1 Examples of photographic views of sliding cover solar greenhouse and principal components 


\subsection{Modeling and numerical simulation}

\subsubsection{Fundamental equation and physical model}

The parametric simulation model based on the finite volume approach was carried out through Fluent-2020R2 software. The simulation software divided the continuous solution domain into units of appropriate volume. It applied the extreme value principle to convert the difference functions constructed by the unit body into a finite volume equation ${ }^{[38]}$. Finally, the microclimate eigenvalues were obtained by solving the algebraic equations introduced into the boundary conditions. The Reynolds averaged $\mathrm{N}-\mathrm{S}$ equations were solved in conjunction with solar radiation, thermal buoyancy and heat transfer processes. The Boussinesq model was activated considering the effect of gravity ${ }^{[39]}$. The water vapor exchange and latent heat transfer were neglected because tomatoes grow at the seeding stage and replenish nutrients through drip irrigation. The basic conservation equations include continuity, momentum and energy governing equations as follows ${ }^{[40]}$ :

$$
\frac{\partial(\rho \varphi)}{\partial t}+\frac{\partial\left(\rho u_{j} \varphi\right)}{\partial x_{j}}=\frac{\partial}{\partial x_{j}}\left(\Gamma_{\varphi} \frac{\partial \varphi}{\partial x_{j}}\right)+S_{\varphi}
$$

where, $\rho$ is the fluid density, $\mathrm{kg} / \mathrm{m}^{3} ; \varphi$ is the dependent variable; $t$ is the time, $\mathrm{s} ; u_{j}$ is the velocity component, $\mathrm{m} / \mathrm{s} ; x_{j}$ is the Cartesian coordinate direction, $\mathrm{m} ; \Gamma_{\varphi}$ is the diffusion coefficient, $\mathrm{m}^{2} / \mathrm{s} ; S_{\varphi}$ is the user-defined source term.

The realizable $k-\varepsilon$ turbulence model was applied to reproduce the turbulence characteristics of the airflow field accurately ${ }^{[41]}$, which calculated conservation equations for the turbulence kinetic and the dissipation rate:

$$
\begin{aligned}
& \frac{\partial}{\partial t}(\rho k)+\frac{\partial}{\partial x_{i}}\left(\rho k u_{j}\right)=\frac{\partial}{\partial x_{j}}\left[\left(\mu+\frac{\mu_{t}}{\sigma_{k}}\right) \frac{\partial k}{\partial x_{j}}\right]+G_{k}+G_{b}-\rho \varepsilon-Y_{m} \\
& \frac{\partial}{\partial t}(\rho \varepsilon)+\frac{\partial}{\partial x_{i}}\left(\rho \varepsilon u_{j}\right)=\frac{\partial}{\partial x_{j}}\left[\left(\mu+\frac{\mu_{t}}{\sigma_{\varepsilon}}\right) \frac{\partial \varepsilon}{\partial x_{j}}\right]+C_{1 \varepsilon} \frac{\varepsilon}{k} G_{k}-C_{2 \varepsilon} \rho \frac{\varepsilon^{2}}{k}(3)
\end{aligned}
$$

where, $k$ is the turbulence kinetic energy, $\mathrm{kg} / \mathrm{m}^{3} ; \varepsilon$ is turbulence dissipation rate, $\mathrm{kg} / \mathrm{m}^{2} ; \mu$ is the viscosity, $\mathrm{Pa} \cdot \mathrm{s} ; \mu_{t}$ is the turbulence viscosity; $G_{k}$ is the generation of kinetic energy, N.m; $G_{b}$ is the generation of kinetic energy by boundary push, $\mathrm{N} \cdot \mathrm{m} ; Y_{m}$ is the pulsatile expansion, $\mathrm{N} \cdot \mathrm{m} ; C_{1 \varepsilon}=1.44 ; C_{2 \varepsilon}=1.90 ; \sigma_{k}=1.0 ; \sigma_{\varepsilon}=1.2$.

The discrete ordinate radiation model of the embedded solar tracking module was adopted to simulate solar radiation energy received by the greenhouse ${ }^{[42]}$. The geographical position, sunshine factor, and illumination parameters were imported to solve the radiation transfer equation:

$$
\begin{aligned}
& \nabla\left(I_{\lambda}(\vec{r}, \vec{s}) \vec{s}\right)+\left(\alpha_{\lambda}+\sigma_{s}\right) I_{\lambda}(\vec{r}, \vec{s})= \\
& \alpha_{\lambda} a^{2} \frac{\sigma T^{4}}{\pi}+\frac{\sigma_{s}}{4 \pi} \int_{0}^{4 \pi} I_{\lambda}\left(\vec{r}, \vec{s}^{\prime}\right) \Phi\left(\vec{s} \cdot \vec{s}^{\prime}\right) \mathrm{d} \Omega^{\prime}
\end{aligned}
$$

where, $r$ is the position vector; $S$ is the scattering direction vector; $\sigma_{s}$ is the scattering coefficient; $\alpha_{\lambda}$ is the absorption coefficient; $a$ is the refraction index; $I_{\lambda}$ is the monochromatic luminance, $\mathrm{W} /\left(\mathrm{m}^{2} \mathrm{sr}^{1}\right)$; $\Omega^{\prime}$ is the solid angle; $\Phi$ is the phase function; $\sigma$ is the Stefan-Boltzmann constant, $\sigma=5.669 \times 10^{-8} \mathrm{~W} / \mathrm{m}^{2} \mathrm{~K}^{4}$.

\subsubsection{Computational case and grid generation}

The sliding cover solar greenhouse and its external flow field were constructed with high-resolution grids. The vent is the interface of the internal and external flow field, and the switch is realized by changing the surface properties. The $3 \mathrm{D}$ computation domain of the greenhouse is a semicircular structure with a radius of $5.2 \mathrm{~m}$, a length of $60 \mathrm{~m}$, and a soil depth of $2 \mathrm{~m}$ is illustrated in Figure 2. The material properties employed are summarized in
Table 1. The geometry and grid of the simulation analysis were established using the Solidworks and Fluent Meshing commercial software. Tomato seedlings planted in the north-south direction were grown in the planting trough and the mutual interval is $0.3 \mathrm{~m}$. The orientation spacing of the planting trough is evenly distributed at $2.55 \mathrm{~m}$ and 22 tomato seedlings were controlled in one row. The target cross section was located in the center of the greenhouse as the monitoring surface, which represents the overall microclimate distribution because the length of the greenhouse is much larger than the $\operatorname{span}^{[43]}$. In this case, $H$ represents the maximum height of the sliding cover solar greenhouse. The length of windward and leeward regions is $10 H=52$ to avoid the prevailing airflow is not subject to external size constraints ${ }^{[44]}$. A logarithmic wind velocity profile is defined as the inlet of the neutral boundary layer to suppress the unrealistic velocity field and thermal behavior.

$$
U(y)=\frac{u_{*}}{\kappa} \ln \left(\frac{y+y_{0}}{y_{0}}\right)
$$

where, $k=\mu_{*}^{2} / C_{\mu}{ }^{1 / 2} ; \varepsilon=u_{*}^{3} / \kappa\left(y+y_{0}\right) ; \quad U(y)$ is the wind velocity at $y$ height, $\mathrm{m} / \mathrm{s} ; \kappa$ is the von Karman's constant, $0.42 ; y_{0}$ is the surface roughness; $u_{*}$ is the shear velocity, $\mathrm{m} / \mathrm{s} ; C_{\mu}$ is the empirical constant.

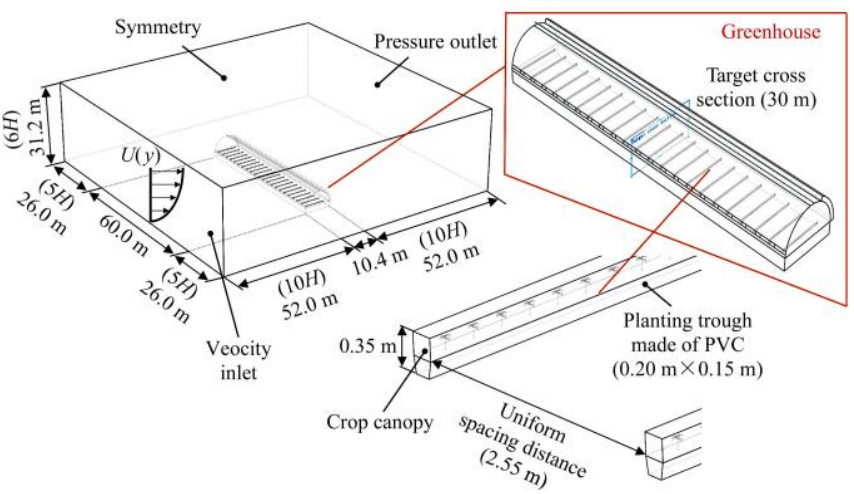

Note: $H$ represents the maximum height of the sliding cover solar greenhouse, $H=5.2 \mathrm{~m} ; U(y)$ represents the wind velocity at $y$ height, $\mathrm{m} / \mathrm{s}$.

Figure 2 Geometry of computational domain including greenhouse integration and external flow field

Table 1 Thermophysical and optical properties of the materials of the simulation model ${ }^{[36]}$

\begin{tabular}{lcccccc}
\hline \multicolumn{1}{c}{ Property } & Air & PO film & Soil & Crop & PVC & Water \\
\hline Density $/ \mathrm{kg} \cdot \mathrm{m}^{-3}$ & 1.225 & 950 & 1700 & 560 & 1420 & 998.2 \\
Specific heat $/ \mathrm{J} \cdot \mathrm{kg}^{-3} \cdot \mathrm{K}^{-1}$ & 0.024 & 0.190 & 0.850 & 2100 & 1004.9 & 4182 \\
Thermal conductivity $/ \mathrm{W} \cdot \mathrm{m}^{-1} \cdot \mathrm{K}^{-1}$ & 1007 & 1600 & 1010 & 0.19 & 0.16 & 0.60 \\
Absorption coefficient & 0.10 & 0.15 & 0.50 & 0.45 & 0.10 & - \\
Refractive index & 1.00 & 1.70 & 1.92 & 2.77 & 7.50 & 1.30 \\
Emissivity & 0.86 & 0.85 & 0.92 & 0.95 & 0.70 & - \\
\hline
\end{tabular}

Grid characteristics are significantly correlated with the convergence and accuracy of the calculational results ${ }^{[42]}$. The high-resolution surface mesh is preferentially executed to discretize the geometric region, as shown in Figure 3. Computational domains near tomato seedlings and greenhouse vents are refined because of slightly complex parameter variations. According to the existing horticultural facility, a continuous roof vent and interrupted side vents are opened to accomplish the desired cooling demand. The central angles corresponding to the opening in the roof and side vents are $10^{\circ}$ and $5.5^{\circ}$, respectively. Meanwhile, the greenhouse features are divided into 21 compartments with primary steel frames. The dimension width of side vents at the center of 
the individual compartment is $0.87 \mathrm{~m}$. This study focused on analyzing the influence of rotation angles (i.e., side vent flip angle $\alpha$; roof vent flip angle $\beta$ ) of the rack-and-pinion ventilated structure on greenhouse microclimate. In the process of grid treatment, it took $1.72 \mathrm{~min}$ for the whole surface meshing to be completed. The maximum skewness was controlled at 0.57 , with a high-resolution accuracy in order to couple the convective heat transfer between tomato canopy and air. A grid sensitivity analysis was performed applying uniform principles as earlier achievements ${ }^{[36]}$. Finally, 2.21 million hybrid meshes including polyhedrons, hexahedrons and tetrahedron meshes were generated. The parameterized simulation has been performed in parallel on a workstation (Intel I9-10940X 3.3 GHz processors; 128 GB Fully DDR4 buffered memory). The integrated grid was generated in 16.45 min with a minimum orthogonal quality of 0.2 .

\subsubsection{Boundary condition and solver setting}

A detailed thermal microclimate and boundary conditions are summarized in Table 2. The external air temperature and soil surface temperature were $24.47^{\circ} \mathrm{C}$ and $25.8^{\circ} \mathrm{C}$, respectively. The external wind speed was defined as $3.4 \mathrm{~m} / \mathrm{s}$, which blows vertically in the simulated greenhouse. As shown in Figure 2, the logarithmic profile inlet was defined as the velocity-inlet and the leeward outlet was defined as the 0 static pressure-outlet. Symmetric surfaces were imposed on the top and sides of the external computational domain ${ }^{[45]}$. The outside soil surface was maintained as a non-slip surface with a fixed temperature and did not participate in radiation. In addition, the solar radiation intensity was simulated by adjusting the insolation clearness index in the ray tracing model, and the parameter was determined to be 0.4 after repeated debugging. The water circulating system used an integral surface to achieve heat transfer because the cross-section of the water pipe is small and its layout is complex. The simplified surface temperature was defined as $17^{\circ} \mathrm{C}$, the unfolded surface is shown in Figure 3. Finally, the numerical model ensures that the ventilation cases with different flip angles were simulated under the same environmental conditions.

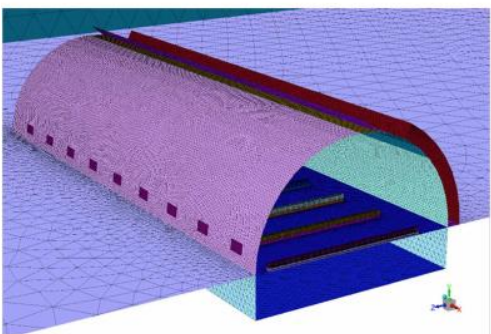

a. Surface grids of the $3 \mathrm{D}$ model

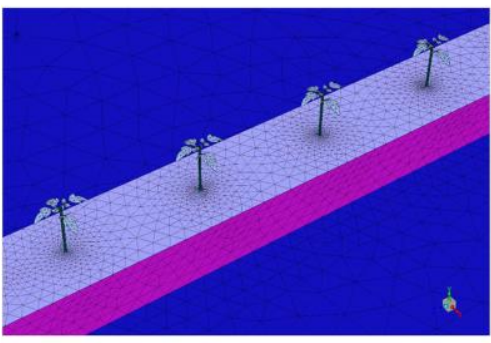

b. Layout of tomato seeding canopies

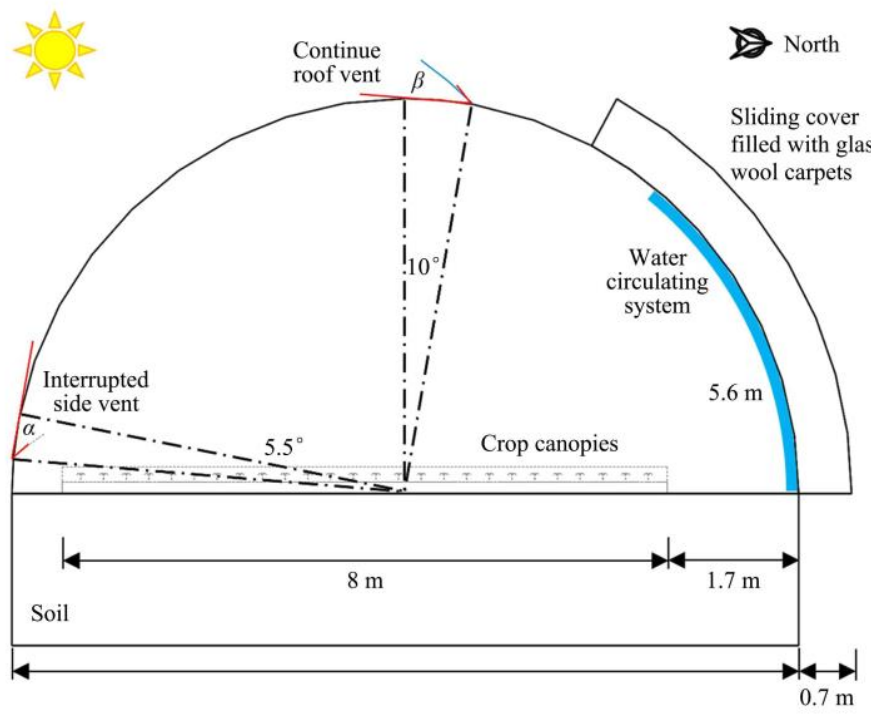

c. Ventilation configuration and greenhouse geometry

Note: $\alpha$ : side vent flip angle; $\beta$ : Roof vent flip angle, the same as below

Figure 3 Design of grid characteristics and ventilation parameters

Table 2 Boundary conditions in the three-dimensional model

\begin{tabular}{cccc}
\hline Classifications & Boundary conditions & Parameters & Boundary conditions \\
\hline Analyzed ventilation script & Side vent flip angle $(\alpha)$ & $35^{\circ}, 45^{\circ}, 55^{\circ}$ & Roof vent flip angle $(\beta)$ \\
\hline \multirow{2}{*}{ External environment } & Outside temperature & $24.47^{\circ} \mathrm{C}$ & Outside soil surface temperature \\
& Prevailing wind velocity & $3.4 \mathrm{~m} / \mathrm{s}$ & Insolation clearness index \\
\hline Internal environment & Water circulating system & $17^{\circ} \mathrm{C}$ & Canopy temperature under unventilated conditions \\
\hline
\end{tabular}

A steady-state calculation dependent on the pressure solver was performed to more quickly replicate the microclimate distribution of greenhouse under unventilated conditions. Subsequently, transient simulation was carried out to analyze the influence of different rotation angles on internal microclimate under natural ventilation. The interface of multiple vents originally was set as the wall in steady-state simulation, and was defined as the interior in transient solution, while the setting of the ventilation window was just the opposite. The characteristics of the polyolefin film were assigned to the vents. Its purpose was to reproduce the complex and variable distribution of the airflow field. The constant input values for the numerical simulation are listed in Table 3. The residuals of all variables in the convergence criterion are $10^{-6}$. The transient calculation step and period are $1 \mathrm{~s}$, and the steady-state iterative step is about 800 steps.
Table 3 Constant input values of the pressure-based solver for the CFD simulation

\begin{tabular}{|c|c|c|c|}
\hline $\begin{array}{l}\text { Relaxation } \\
\text { factors }\end{array}$ & $\begin{array}{c}\text { Couple } \\
\text { arithmetic }\end{array}$ & Classifications & Methods \\
\hline Pressure & 0.5 & Gradient scheme & Least squares cell based \\
\hline Density & 1 & Pressure scheme & Body force weighted \\
\hline Mass force & 1 & Energy scheme & Second order upwind \\
\hline Moment & 0.5 & Momentum scheme & Second order upwind \\
\hline Energy & 0.75 & Discrete ordinates scheme & Frist order discretion \\
\hline$k$ and $\varepsilon$ & 0.75 & $\begin{array}{l}\text { Turbulence kinetic energy } \\
\text { scheme }\end{array}$ & Second order upwind \\
\hline $\begin{array}{l}\text { Turbulence } \\
\text { viscosity }\end{array}$ & 1 & Dissipation rate scheme & Second order upwind \\
\hline Discrete ordinates & 1 & Mean age of air scheme & Frist order discretion \\
\hline
\end{tabular}




\subsection{Entropy method and fuzzy comprehensive evaluation}

2.3.1 Evaluation index system for ventilation strategy

The evaluation index system of natural ventilation is constructed to understand the interaction of the rotation angles of rack-and-pinion flip windows and greenhouse microclimate. Six specific attributes were selected to establish an analytical hierarchy process for the numerical simulation, which is fully shown in Figure 4. The mean age of air is a quantitative index to evaluate the quality of airflow organization ${ }^{[46]}$. It was imported into the boundary conditions as a user-defined scalar during the numerical iteration, which can be defined according to ASHRAE standard from the following transport equation:

$$
\frac{\partial}{\partial x_{j}}\left(\rho u_{j} M_{a}-\left(2.88 \rho \times 10^{-5}+\frac{\mu_{\mathrm{eff}}}{0.7}\right) \frac{\partial M_{a}}{\partial x_{j}}\right)=S_{\varphi}
$$

where, $M_{a}$ is the mean age of air, $\mathrm{s} ; \mu_{\text {eff }}$ is the effective turbulent viscosity, $\mathrm{Pa} \cdot \mathrm{s}$.

Heat removal efficiency reflects the internal cooling effect of air inside the greenhouse. The equation is as follows:

$$
\eta=\left(T_{i}-T_{v}\right) / \Delta t_{i-v}
$$

where, $\eta$ is heat removal efficiency, $\% ; T_{i}$ is the air temperature without natural ventilation, ${ }^{\circ} \mathrm{C} ; T_{v}$ is the air temperature under natural ventilation, ${ }^{\circ} \mathrm{C} ; \Delta t_{i-v}$ is the time of natural ventilation, $\mathrm{s}$.

The parameter uniformity index as an evaluation criterion was proposed to fully reveal local ventilation stability. Inhomogeneity is defined as:

$$
J_{v}=\frac{1}{P_{m}} \sqrt{\frac{\sum_{i=1}^{n}\left(P_{i}-P_{m}\right)^{2}}{n-1}}
$$

where, $J_{v}$ is the variable inhomogeneity, $\% ; P_{i}$ is a certain parameter; $P_{m}$ is the average value of parameters; $n$ is the number of tomato seeding canopies. The analytic hierarchy process was established and further analysis of the control angles of ventilation machinery was conducted to attain the optimal ventilation strategy in the sliding cover solar greenhouse. Nine cases combining the side vent flip angle $(\alpha)$ and the roof vent flip angles $(\beta)$ were considered. The detailed simulation results are listed in Table 4.

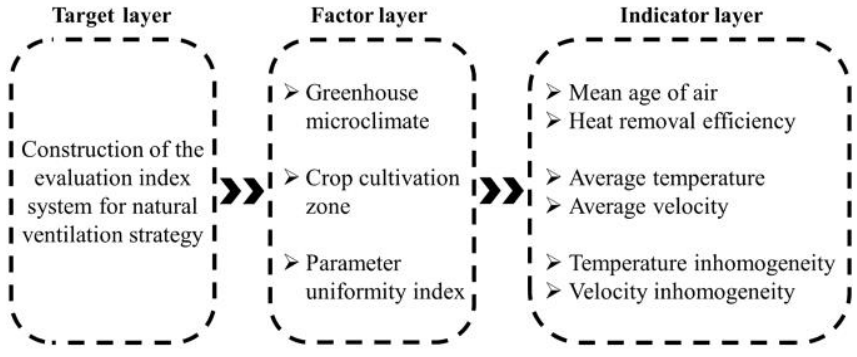

Figure 4 Analytic hierarchy process for further calculation of entropy weight and fuzzy optimization method based on numerical

\begin{tabular}{|c|c|c|c|c|c|c|}
\hline Case & Mean age of air $/ \mathrm{s}$ & $\begin{array}{c}\text { Heat removal } \\
\text { efficiency/\% }\end{array}$ & $\begin{array}{c}\text { Average } \\
\text { temperature } /{ }^{\circ} \mathrm{C}\end{array}$ & $\begin{array}{c}\text { Average } \\
\text { velocity } / \mathrm{m} \cdot \mathrm{s}^{-1}\end{array}$ & $\begin{array}{c}\text { Temperature } \\
\text { inhomogeneity } / \%\end{array}$ & $\begin{array}{c}\text { Velocity } \\
\text { inhomogeneity } / \%\end{array}$ \\
\hline$\alpha=35^{\circ}, \beta=25^{\circ}$ & 49.66 & 24.13 & 28.84 & 0.21 & 1.53 & 29.12 \\
\hline$\alpha=45^{\circ}, \beta=25^{\circ}$ & 49.20 & 25.51 & 28.18 & 0.25 & 1.04 & 15.08 \\
\hline$\alpha=55^{\circ}, \beta=25^{\circ}$ & 48.83 & 27.65 & 28.22 & 0.26 & 1.39 & 15.74 \\
\hline$\alpha=35^{\circ}, \beta=35^{\circ}$ & 48.88 & 25.85 & 29.01 & 0.22 & 1.80 & 27.75 \\
\hline$\alpha=45^{\circ}, \beta=35^{\circ}$ & 48.52 & 26.90 & 28.35 & 0.22 & 1.14 & 20.57 \\
\hline$\alpha=55^{\circ}, \beta=35^{\circ}$ & 48.82 & 28.01 & 28.09 & 0.26 & 1.07 & 13.76 \\
\hline$\alpha=35^{\circ}, \beta=45^{\circ}$ & 47.95 & 26.90 & 29.20 & 0.22 & 2.25 & 30.01 \\
\hline$\alpha=45^{\circ}, \beta=45^{\circ}$ & 47.91 & 27.93 & 28.35 & 0.25 & 1.35 & 17.99 \\
\hline$\alpha=55^{\circ}, \beta=45^{\circ}$ & 48.88 & 28.82 & 27.94 & 0.28 & 0.91 & 15.06 \\
\hline
\end{tabular}
simulation

Table 4 Characteristic values of six specific attributes in nine cases for the fuzzy comprehensive evaluation

\subsubsection{Decision optimization process}

The entropy method was used to determine objective weights and its calculation process includes the following steps. Assume that there are $a(a=9)$ cases for evaluation and $b(b=6)$ assessment criteria, which form a decision-making characteristic matrix $Z=\left\{z_{i j} ; i=1,2 \ldots, a ; j=1,2 \ldots, b\right\}$. Generally, a degree of membership matrix is applied to eliminate the different dimensions and orders of attributes.

$$
\begin{gathered}
f_{i j}=\left(z_{i j}-\min _{1 \leq i \leq a} z_{i j}\right) /\left(\max _{1 \leq i \leq a} z_{i j}-\min _{1 \leq i \leq a} z_{i j}\right) \text { for benefit criteria set } \\
f_{i j}=\left(\max _{1 \leq i \leq a} z_{i j}-z_{i j}\right) /\left(\max _{1 \leq i \leq a} z_{i j}-\min _{1 \leq i \leq a} z_{i j}\right) \text { for cost criteria set (10) } \\
P_{i j}=f_{i j} / \sum_{j=1}^{b} f_{i j}
\end{gathered}
$$

where, $f_{i j}$ is the characteristic value of relative membership; $P_{i j}$ is the probability value of each attribute; required not to be $1 / a$ as possible which means the importance of all alternatives are equal.

The information entropy of each criterion $H_{j}$ is obtained. The degree of divergence of instinctive information $D_{j}$ is calculated. If $P_{i j}=0, P_{i j} \ln P_{i j}=0$.

$$
\begin{gathered}
H_{j}=-\ln (b)^{-1} \sum_{j=1}^{b} P_{i j} \ln P_{i j} \\
D_{j}=1-H_{j}
\end{gathered}
$$

Therefore, the entropy weight of the conditional attribute $W_{j}$ can be determined as follows:

$$
W_{j}=D_{j} / \sum_{j=1}^{b} D_{j}
$$

In the decision-making system, the membership of a certain case $U_{i}$ can be achieved by adopting weighted and generalized Euclidean distance method and least square method ${ }^{[8]}$ :

$$
U_{i}=\left\{1+\frac{\sum_{i=1}^{a}\left[W_{j}\left(G_{i}-f_{i j}\right)\right]^{2}}{\sum_{i=1}^{a}\left[W_{j}\left(f_{i j}-B_{i}\right)\right]^{2}}\right\}^{-1}
$$

where, $G_{i}$ is the optimal relative membership degree; $B_{i}$ is the worst relative membership degree.

According to the previous calculation results, the information entropy and entropy weight of the six assessment criteria are as follows:

$$
\begin{aligned}
& H_{j}=\left[\begin{array}{llllll}
0.908 & 0.918 & 0.898 & 0.853 & 0.926 & 0.861
\end{array}\right] \\
& W_{j}=\left[\begin{array}{llllll}
0.145 & 0.129 & 0.160 & 0.231 & 0.116 & 0.218
\end{array}\right]
\end{aligned}
$$

Obviously, the six proposed attributes are quantitatively summarized in terms of their relative importance based on entropy weight. The average velocity and its inhomogeneity are the crucial predictors, with the largest weights being 0.231 and 0.218 , respectively. 


\section{Results and discussion}

\subsection{Experimental validation of the comprehensive model}

In order to analyze the temperature distribution inside the greenhouse, temperature measurement experiments were performed. Figure 5 shows the comparison between numerical simulation and experimental results under the specified ventilation scenario (i.e., side vent flip angle of $45^{\circ}$ and roof vent flip angle of $35^{\circ}$ ). A series of thermocouples (TYD-ZS2 type, range: $-40^{\circ} \mathrm{C}$ to $80^{\circ} \mathrm{C}$, precision: $\pm 0.2^{\circ} \mathrm{C}$, resolution: $0.1^{\circ} \mathrm{C}$ ) coupled to a data logger (HOBO U100-011, USA Oneset Co Ltd.) are attached to the target cross-section via a lead-wire, with a horizontal and vertical spacing of $2 \mathrm{~m}$ and $1 \mathrm{~m}$, respectively. During the experiments, the control execution system opens the roof and side vents to fulfill the specified operating conditions while the water circulating system is always running before the natural ventilation. The cooling effect of natural ventilation is slowed down after about $10 \mathrm{~min}$ of ventilation and real-time temperature data is recorded. The average relative error between the point measurements and simulation results is $1.74 \%$, with maximum relative error of $3.71 \%$ and minimum relative error of $0.33 \%$. Therefore, the precision of numerical simulation is validated against experimental results, and detailed ventilation characteristics under CFD simulation are further imported into the comprehensive evaluation system based on entropy weight and fuzzy optimization method.

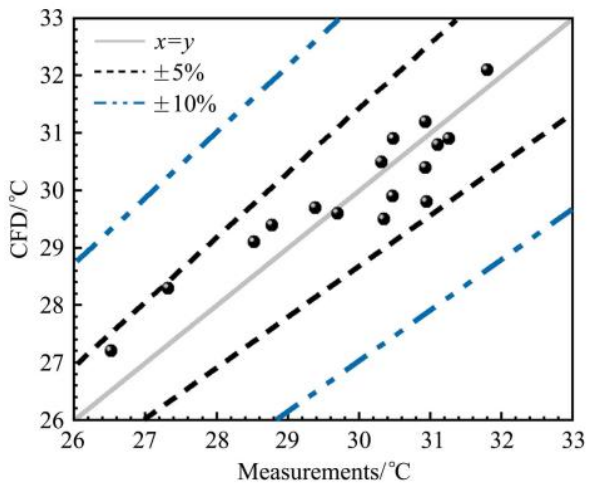

a. Measured and simulated temperature

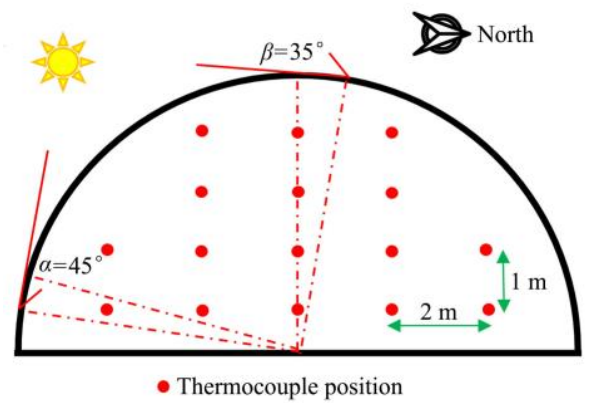

b. Layout of the indoor air temperature measurement points

Figure 5 Comparison between numerical simulation and experimental results in the sliding cover solar greenhouse

\subsection{Analysis of microclimate characteristics}

Representative case analysis on microclimate characteristics is proposed because the ventilation structure is the same, and the corresponding microclimate patterns are actually only different in order of magnitude. Figure 6 illustrates the simulated temperature and velocity distributions of the greenhouse at 12:10 on August 15th, 2018. This representative ventilation scheme sets the side vent flip angle of $45^{\circ}$ and the roof vent flip angle of $35^{\circ}$. It can be observed that the temperature distribution inside the greenhouse has a high correlation with air movement. The temperature distribution in the greenhouse is gradient due to the combined action of wind pressure and thermal pressure. The heat mass of the south roof of the greenhouse is relatively concentrated because the rack-and-pinion ventilated structure has the function of diverting the wind direction, resulting in an internal air temperature difference of about $5.7^{\circ} \mathrm{C}$ on the target cross section. The surface layer of soil is covered with black film, and its highest temperature is $35.4^{\circ} \mathrm{C}$. The thermal storage layer provides abundant heating capacity at nighttime but does not affect the development of crop roots because tomato seedlings are grown in planting troughs equipped with drip irrigation. Side flip vents avoid the direct impact of the prevailing wind on the tomato canopy, and transitional low-speed airflow is continuously supplied to both sides of planting troughs. The average temperature and velocity of the crop cultivation zone are $28.4^{\circ} \mathrm{C}$ and $0.22 \mathrm{~m} / \mathrm{s}$, respectively. Meanwhile, the airflow coming from the side vents will guide the internal air to form a counterclockwise circulation, which further promotes the convective heat transfer between the water circulation system and the indoor air.
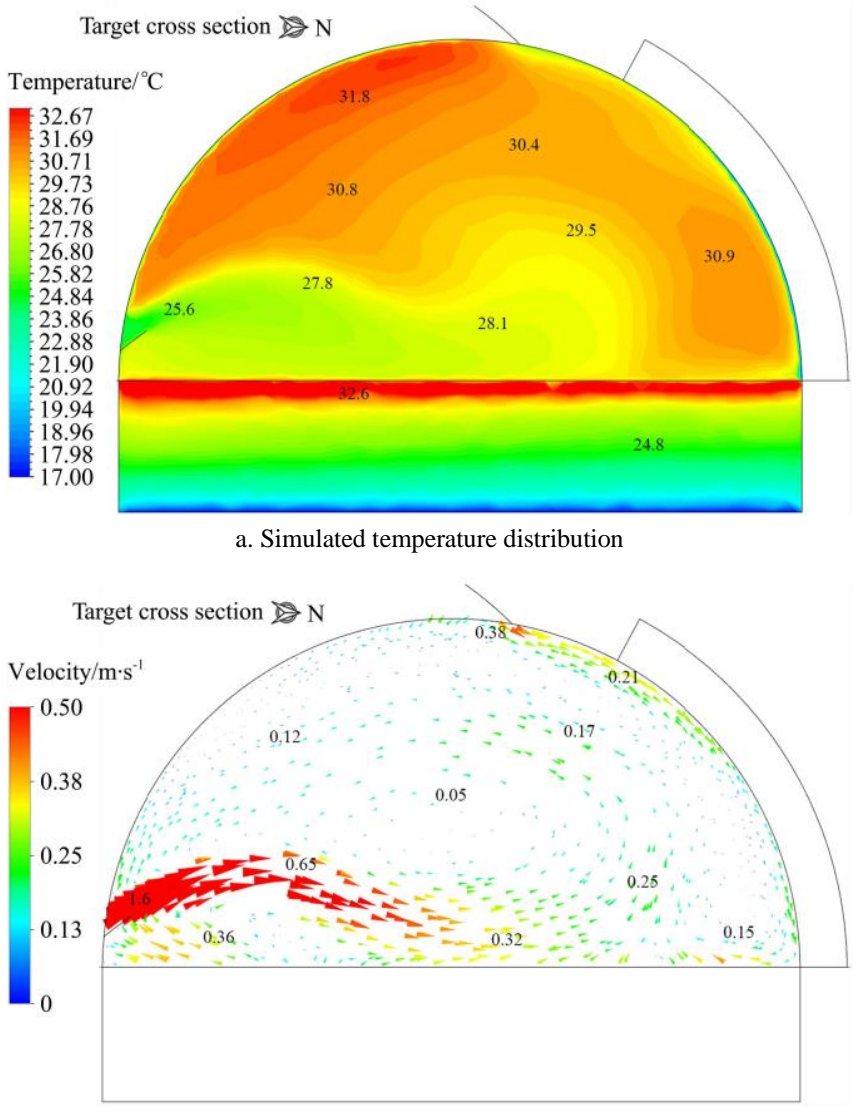

b. Simulated velocity distribution

Figure 6 Distributions of the sliding cover solar greenhouse at 12:10 on August 15th, 2018

The mean age of air was employed to reflect the flow characteristics of fresh air, and its local value at the ventilation inlet was assumed to be theoretically equal to 0 . Figure 7 shows the contour plot of the mean age of air in the target cross section for the existing ventilation configuration (i.e., side vent flip angle of $45^{\circ}$ and roof vent flip angle of $35^{\circ}$ ). The optimal air age is concentrated near the side vents and the north roof, especially the side vents under the prevailing wind is the most significant compared with the roof vent on the leeward side. The local air age of the south roof and the north sidewalk of the greenhouse has a large stagnation area, which results in non-uniform distribution of environmental parameters. Consequently, these results illustrate 
that the interaction of the rotation angles of the rack-and-pinion flip windows has a crucial influence on greenhouse microclimate characteristics and uniformity.

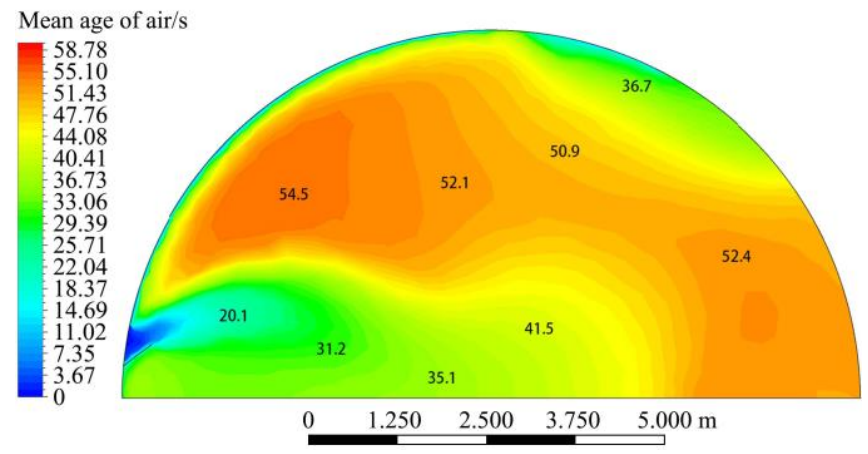

Figure 7 Contour plot of the mean age of air for the existing ventilation configuration (i.e. side vent flip angle of $45^{\circ}$ and roof vent flip angle of $35^{\circ}$ ) in the target cross section

\subsection{Decision evaluation of ventilation schemes}

Heat removal efficiency (becoming larger as the side vent flip angle becomes increases when the roof vent flip angle is constant) in different ventilation schemes can be visibly observed in Table 4 . The results show that the increasing side vent flip angle is conducive to the prevailing wind entering the greenhouse more efficiently without directly impacting the canopy. Under the specified flip angle of side vents (i.e., $\alpha=35^{\circ}, \alpha=45^{\circ}$ and $\alpha=55^{\circ}$ ), the heat removal efficiency becomes weaker with the increase of the roof vent flip angle, and the variation difference is $2.77 \%$, $2.42 \%$ and $1.17 \%$. Figure 8 illustrates the comparative histograms of simulated microclimate characteristics (i.e. temperature and airflow velocity) and corresponding inhomogeneity for the tomato seeding canopies. It can be observed that the average airflow velocity of the tomato seeding canopies is inversely proportional to the average temperature. The results demonstrate that the refreshing airflow is beneficial to the heat exchange between crop leaves and internal air, and further accelerated the photosynthesis of tomato seedings. However, the temperature inhomogeneity is proportional to the velocity inhomogeneity. The worst ventilation scheme is the roof vent flip angle of $35^{\circ}$ and the roof vent flip angle of $45^{\circ}$ under the associated side vent flip angle of $45^{\circ}$. In addition, the velocity inhomogeneity decreases gradually with the increase of the side vent flip angle. This phenomenon suggests that the increase of the flip angle of side vents makes the prevailing airflow continuously and stably into the areas on both sides of the planting trough. It is disadvantageous to the temperature and airflow uniform when the roof vent flip angle is $35^{\circ}$, no matter how the side vent flip angle is adjusted. Thus, the rotating angles of ventilation schemes have a substantial impact on the microclimate and inhomogeneity of the tomato seeding canopies.

Figure 9 describes the ranks of nine ventilated cases using the evaluation index system of ventilation strategy. The maximum relative degree of membership indicates that the ventilation scheme is optimal, and it can be combined with the water circulation system to accomplish the greenhouse cooling function. According to the simulation data, it can be inferred that the relative degree of membership of the side vent flip angle of $45^{\circ}$ is $36 \%$ and $97 \%$ higher than that of the side vent flip angle of $35^{\circ}$ and the side vent flip angle of $25^{\circ}$, respectively. The influence of changing the roof vent flip angle on the relative degree of membership is negligible when the side vent flip angle is $35^{\circ}$.

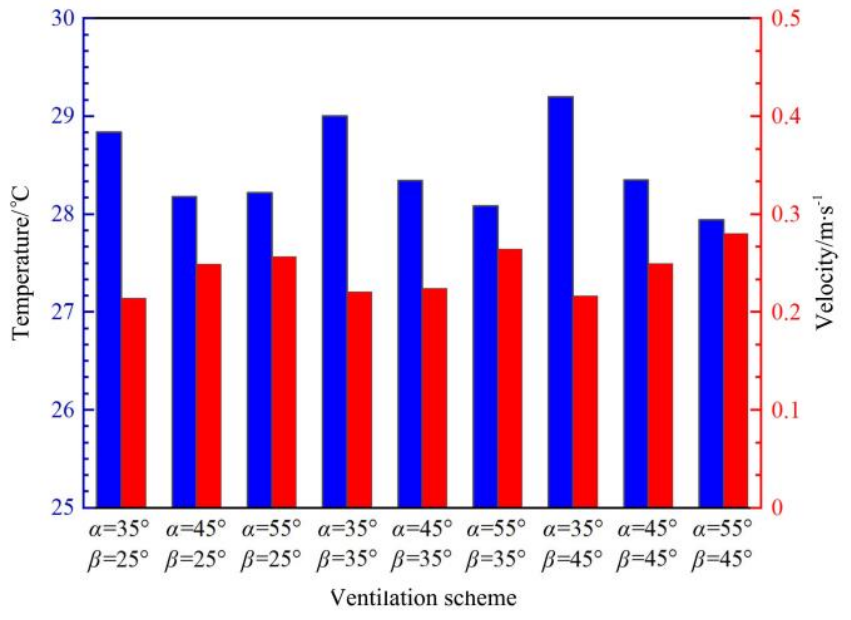

a. Average temperature and velocity of tomato seeding canopies

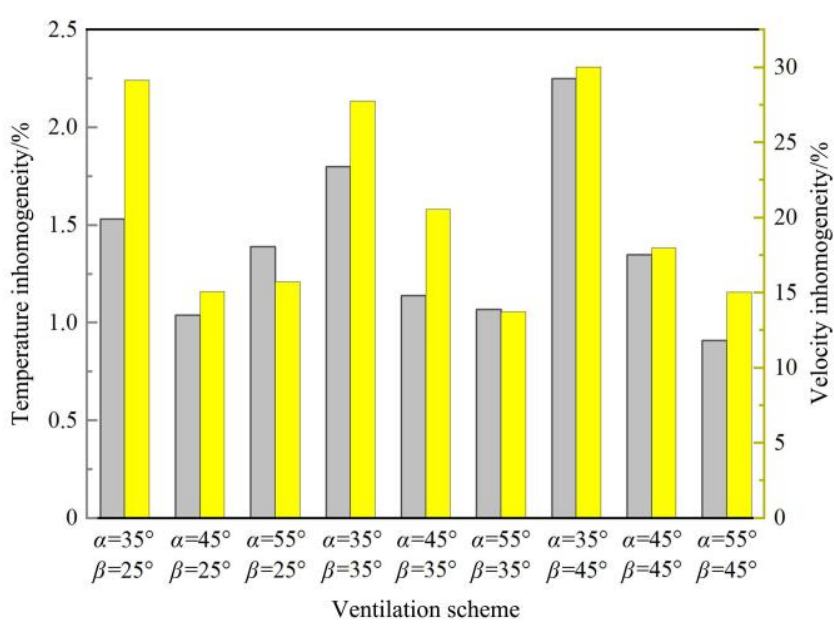

b. Temperature and velocity inhomogeneity of tomato seeding

Figure 8 Comparative histograms of simulated greenhouse microclimate characteristics

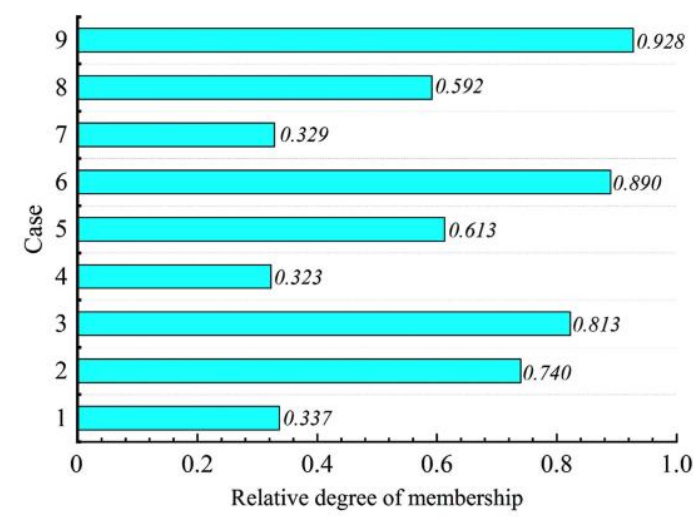

Figure 9 Ranks of different cases with the relative degree of membership using the evaluation index system of ventilation strategy

\section{Conclusions}

This study utilized an integrated numerical simulation and entropy-weight method to analyze the greenhouse microclimate. The preliminary numerical model has been verified by monitoring temperature data under ventilation conditions. The average relative error between the point measurements and simulation results was $1.74 \%$, with maximum relative errors of $3.71 \%$ and minimum relative errors of $0.33 \%$. The detailed ventilation characteristics are further imported into the comprehensive evaluation system based on entropy weight and fuzzy optimization method. 
The analytic hierarchy process was established and further analysis of the control angles of ventilation machinery was conducted to attain the optimal ventilation strategy in the sliding cover solar greenhouse. Nine cases combining the side vent flip angle $(\alpha)$ and the roof vent flip angle $(\beta)$ were considered. Six proposed attributes were quantitatively summarized in terms of their relative importance based on entropy weight. The average velocity and its inhomogeneity were the crucial predictors, with the largest weights being 0.231 and 0.218 , respectively. The results illustrate that the interaction of the rotation angles of the rack-and-pinion flip windows has a crucial influence on greenhouse microclimate characteristics and uniformity.

The results show that the temperature distribution inside the greenhouse has a high correlation with air movement. The heat mass of the south roof of the greenhouse is relatively concentrated because the rack-and-pinion ventilated structure has the function of diverting the wind direction, resulting in an internal air temperature difference of about $5.7^{\circ} \mathrm{C}$ on the target cross section. Meanwhile, the airflow coming from the side vents will guide the internal air to form a counterclockwise circulation, which further promotes the convective heat transfer between the water circulation system and the indoor air. The CFD simulation shows that the worst airflow distribution scheme is the roof vent flip angle of $35^{\circ}$ and the roof vent flip angle of $45^{\circ}$ under the associated side vent flip angle of $45^{\circ}$. Additionally, it is disadvantageous to the temperature and airflow uniform when the roof vent flip angle is $35^{\circ}$, no matter how the side vent flip angle is adjusted. Finally, the relative degree of membership of the side vent flip angle of $45^{\circ}$ is $36 \%$ and $97 \%$ higher than that of the side vent flip angle of $35^{\circ}$ and the side vent flip angle of $25^{\circ}$, respectively. The influence of changing the roof vent flip angle on the relative degree of membership is negligible when the side vent flip angle is $35^{\circ}$. In this study, in order to alleviate the discrete difficulty and reduce the computational cost, the influence of complex hinged skeleton structure on shading is ignored, which should be improved in later studies. On the other hand, complex problems such as numerical simulation of mature tomato plants, respiration and transpiration still need to be comprehensively tackled. It is necessary to optimize and perfect the greenhouse ventilation control system by combining the subjective weight of the expert evaluation system. This paper can provide a reference to evaluate the ventilated strategies of the sliding cover solar greenhouse for the regional and central government.

\section{Acknowledgements}

The authors acknowledge that this work was financially supported by the National Key Research and Development Program of China (Grant No. 2020YFD1000305). The authors acknowledge the Key Laboratory of Protected Horticulture, Shenyang Agricultural University, Ministry of Education, China for providing the test platform for this study.

\section{[References]}

[1] Wang J, Li S, Guo S, Ma C, Wang J, Jin S. Simulation and optimization of solar greenhouses in Northern Jiangsu Province of China. Energy and Buildings, 2014; 78: 143-152.

[2] He X, Wang J, Guo S, Zhang J, Wei B, Sun J, et al. Ventilation optimization of solar greenhouse with removable back walls based on CFD. Computers and Electronics in Agriculture, 2018; 149: 16-25.

[3] Cuce E, Harjunowibowo D, Cuce P M. Renewable and sustainable energy saving strategies for greenhouse systems: A comprehensive review. Renewable Sustainable Energy Reviews, 2016; 64: 34-59.
[4] Choab N, Allouhi A, El Maakoul A, Kousksou T, Saadeddine S, Jamil A Review on greenhouse microclimate and application: Design parameters, thermal modeling and simulation, climate controlling technologies. Solar Energy, 2019; 191: 109-137.

[5] Shamshiri R R, Kalantari F, Ting K C, Thorp K R, Hameed I A, Weltzien $\mathrm{C}$, et al. Advances in greenhouse automation and controlled environment agriculture: A transition to plant factories and urban agriculture. Int $\mathbf{J}$ Agric Biol Eng, 2018; 11(1): 1-22.

[6] Saberian A, Sajadiye S M. The effect of dynamic solar heat load on the greenhouse microclimate using CFD simulation. Renewable Energy, 2019; 138: 722-737.

[7] Chen J, Ma Y, Pang Z. A mathematical model of global solar radiation to select the optimal shape and orientation of the greenhouses in southern China. Solar Energy, 2020; 205: 380-389.

[8] Zhang X, Lyu J, Dawuda M M, Xie J, Yu J, Gan Y, et al. Innovative passive heat-storage walls improve thermal performance and energy efficiency in Chinese solar greenhouses for non-arable lands. Solar Energy, 2019; 190: 561-575.

[9] Cao S J, Ren C. Ventilation control strategy using low-dimensional linear ventilation models and artificial neural network. Building and Environment, 2018; 144: 316-333.

[10] Cao K, Xu H, Zhang R, Xu D, Yan L, Sun Y, et al. Renewable and sustainable strategies for improving the thermal environment of Chinese solar greenhouses. Energy and Buildings, 2019; 202: 109414. doi: 10.1016/j.enbuild.2019.109414.

[11] Boulard T, Roy J C, Pouillard J B, Fatnassi H, Grisey A. Modelling of micrometeorology, canopy transpiration and photosynthesis in a closed greenhouse using computational fluid dynamics. Biosystems Engineering, 2017; 158: 110-133.

[12] Sethi V P, Sumathy K, Lee C, Pal D S. Thermal modeling aspects of solar greenhouse microclimate control: A review on heating technologies. Solar Energy, 2013; 96: 56-82.

[13] Li A, Huang L, Zhang T. Field test and analysis of microclimate in naturally ventilated single-sloped greenhouses. Energy and Buildings, 2017; 138: 479-489.

[14] Mistriotis A, Bot G P A, Picuno P, Scarascia-Mugnozza G. Analysis of the efficiency of greenhouse ventilation using computational fluid dynamics. Agricicultural and Forest Meteorology, 1997; 85(3-4): 217-228.

[15] Kitaya Y, Tsuruyama J, Shibuya T, Yoshida M, Kiyota M. Effects of air current speed on gas exchange in plant leaves and plant canopies. Advances in Space Research, 2003; 31(1): 177-182.

[16] Saberian A, Sajadiye S M. Assessing the variable performance of fan-and-pad cooling in a subtropical desert greenhouse. Applied Thermal Engineering, 2020; 179: 115672. doi: 10.1016/j.applthermaleng.2020. 115672.

[17] Ghoulem M, El Moueddeb K, Nehdi E, Zhong F, Calautit J. Analysis of passive downdraught evaporative cooling windcatcher for greenhouses in hot climatic conditions: Parametric study and impact of neighbouring structures. Biosystems Engineering, 2020; 197: 105-121.

[18] Lu W, Zhang Y, Fang H, Ke X, Yang Q. Modelling and experimental verification of the thermal performance of an active solar heat storage-release system in a Chinese solar greenhouse. Biosystems Engineering, 2017; 160: 12-24.

[19] Teitel M, Wenger E. Air exchange and ventilation efficiencies of a monospan greenhouse with one inflow and one outflow through longitudinal side openings. Biosystems Engineering, 2014; 119: 98-107.

[20] Flores-Velazquez J, Montero J I, Baeza E J, Lopez J C. Mechanical and natural ventilation systems in a greenhouse designed using computational fluid dynamics. Int J Agric Biol Eng, 2014; 7(1): 1-16.

[21] Benni S, Tassinari P, Bonora F, Barbaresi A, Torreggiani D. Efficacy of greenhouse natural ventilation: Environmental monitoring and CFD simulations of a study case. Energy and Buildings, 2016;125: 276-286.

[22] Ould Khaoua S A, Bournet P E, Migeon C, Boulard T, Chassériaux G. Analysis of greenhouse ventilation efficiency based on computational fluid dynamics. Biosystems Engineering, 2006; 95(1): 83-98.

[23] Villagrán E A, Baeza Romero E J, Bojacá C R. Transient CFD analysis of the natural ventilation of three types of greenhouses used for agricultural production in a tropical mountain climate. Biosystems Engineering, 2019 188: 288-304.

[24] Campen J B, Bot G P A. Determination of greenhouse-specific aspects of ventilation using three-dimensional computational fluid dynamics. Biosystems Engineering, 2003; 84(1): 69-77.

[25] Bournet P E, Ould Khaoua S A, Boulard T. Numerical prediction of the 
effect of vent arrangements on the ventilation and energy transfer in a multi-span glasshouse using a bi-band radiation model. Biosystems Engineering, 2007; 98(2): 224-234.

[26] Chen J L, Xu F, Tan D P, Shen Z, Zhang L B, Ai Q L. A control method for agricultural greenhouses heating based on computational fluid dynamics and energy prediction model. Applied Energy, 2015;141: 106-118.

[27] Tong G, Christopher D M, Li B. Numerical modelling of temperature variations in a Chinese solar greenhouse. Computers and Electronics in Agriculture, 2009; 68(1): 129-139.

[28] Norton T, Sun D W, Grant J, Fallon R, Dodd V. Applications of computational fluid dynamics (CFD) in the modelling and design of ventilation systems in the agricultural industry: A review. Bioresource Technology, 2007; 98(12): 2386-2414.

[29] Bournet P-E, Boulard T. Effect of ventilator configuration on the distributed climate of greenhouses: A review of experimental and CFD studies. Computers Electronics in Agriculture, 2010; 74(2): 195-217.

[30] Delgado A, Romero I. Environmental conflict analysis using an integrated grey clustering and entropy-weight method: A case study of a mining project in Peru. Environmental Modelling \& Software, 2016; 77 : $108-121$

[31] Lee S Y, Lee I B, Yeo U H, Kim R W, Kim J G. Optimal sensor placement for monitoring and controlling greenhouse internal environments. Biosystems Engineering, 2019; 188: 190-206.

[32] Feng G Z, Lei S Y, Guo Y J, Meng B, Jiang Q F. Optimization and evaluation of ventilation mode in marine data center based on AHP-entropy weight. Entropy, 2019; 21(8): 796. doi: 10.3390/e21080796.

[33] Ziapour B M, Dehnavi R. A numerical study of the arc-roof and the one-sided roof enclosures based on the entropy generation minimization. Computers \& Mathematics with Applications, 2012; 64(6): 1636-1648.

[34] Chen S K, Leng Y, Mao B H, Liu S. Integrated weight-based multi-criteria evaluation on transfer in large transport terminals: A case study of the Beijing South Railway Station. Transportation Research Part A: Policy and Practice, 2014; 66: 13-26.

[35] Zhang X, Wang H, Zou Z, Wang S. CFD and weighted entropy based simulation and optimisation of Chinese Solar Greenhouse temperature distribution. Biosystems Engineering, 2016; 142: 12-26.

[36] Li H, Li Y M, Yue X, Liu X G, Tian S B, Li T L. Evaluation of airflow pattern and thermal behavior of the arched greenhouses with designed roof ventilation scenarios using CFD simulation. PLoS One, 2020; 15(9): e0239851. doi: 10.1371/journal.pone.0239851.

[37] Tong X, Sun Z, Sigrimis N, Li T. Energy sustainability performance of a sliding cover solar greenhouse: Solar energy capture aspects. Biosystems Engineering, 2018; 176: 88-102.

[38] Zhang G, Fu Z, Yang M, Liu X, Dong Y, Li X. Nonlinear simulation for coupling modeling of air humidity and vent opening in Chinese solar greenhouse based on CFD. Computers and Electronics in Agriculture, 2019; 162: 337-347.

[39] Akrami M, Javadi A A, Hassanein M J, Farmani R, Dibaj M, Tabor GR, et al. Study of the effects of vent configuration on mono-span greenhouse ventilation using computational fluid dynamics. Sustainability, 2020;12(3): 986 . doi: 10.3390/su12030986.

[40] Pakari A, Ghani S. Airflow assessment in a naturally ventilated greenhouse equipped with wind towers: Numerical simulation and wind tunnel experiments. Energy and Buildings, 2019; 199: 1-11.

[41] Qi D, Li A G, Li S X, Zhao C Y. Comparative analysis of earth to air heat exchanger configurations based on uniformity and thermal performance. Applied Thermal Engineering, 2021; 183(Part1): 116152. doi: 10.1016/j.applthermaleng.2020.116152.

[42] Liu X, Li H, Li Y M, Yue X, Tian S B, Li T L. Effect of internal surface structure of the north wall on Chinese solar greenhouse thermal microclimate based on computational fluid dynamics. PLos One, 2020;15(4): e0231316. doi: 10.1371/journal.pone.0231316.

[43] Tong G, Christopher D M, Zhang G. New insights on span selection for Chinese solar greenhouses using CFD analyses. Computers Electronics in Agriculture, 2018; 149: 3-15.

[44] van Hooff T, Blocken B. CFD evaluation of natural ventilation of indoor environments by the concentration decay method: $\mathrm{CO}_{2}$ gas dispersion from a semi-enclosed stadium. Building and Environment, 2013; 61: 1-17.

[45] Lee S-Y, Lee I-B, Kim R-W. Evaluation of wind-driven natural ventilation of single-span greenhouses built on reclaimed coastal land. Biosystems Engineering, 2018; 171: 120-142.

[46] Montazeri H, Montazeri F. CFD simulation of cross-ventilation in buildings using rooftop wind-catchers: Impact of outlet openings. Renewable Energy, 2018; 118: 502-520. 